\title{
Innovative Applications of Post-Tension for Restoration and Rehabilitation of Bridges and Structures - Case Studies in India
}

\author{
Ramesh Kommajosyula $^{1}$ and Narapraju Venkat Ramana Rao ${ }^{2}$ \\ 1. Varshitha Concrete Technologies Pvt. Ltd., Hyderabad 500 033, India \\ 2. Department of Civil, Jawaharlal Nehru Technological University, Hyderabad 500085, India
}

\begin{abstract}
This paper deals with new and innovative case studies of application of post-tensioning for restoration of structures for buildings, bridges and rock stabilization in India. In earlier situations for these types of cases conventional method of repair and rehabilitation has been used. These innovative approaches for restoration have led to enormous saving of cost and time. The advantages of post tensioning are well known in the civil industry and are being used for the last 40 to 50 years. Post tensioning is one of the best methods to induce stresses in the concrete before application of live load and this technique can also be widely used for restoration and rehabilitation of structures. Unlike the use of post-tensioning in new structures there are no definite methods or codes for application in restoration and rehabilitation of structures. For restoration and rehabilitation of structures, PT (post tensioned) technique can be applied in combination with other techniques and materials available. Bridge lifting is a tricky and risky job especially when the superstructure is displaced appreciably by a natural calamity, etc.. Not only the present state of structure needs proper study before commencement of restoration and rehabilitation but also calls for careful execution. This paper deals with case studies of innovative applications of post tensioning in restoration and rehabilitation of structures and restoration of bridge structure in Andaman \& Nicobar Island, India affected by Sumatra quake.
\end{abstract}

Key words: Restoration, rehabilitation, structures, external post tensioning, rock stabilization.

\section{Introduction}

Post tensioning was first introduced in buildings in India 15 to 20 years ago. Now it has become very popular in India and sensing the inherent advantages even small structures like Ground +2 Floors are adopting post tensioning.

Strengthening and/or upgrading of concrete structure can be carried out using various techniques such as bonded steel or FRP (fiber reinforced polymer-fabric or laminates), encasement by micro concrete, etc.. With the invention of use of prestressing of TENDONS for construction, applications of the same are also being adopted for strengthening/upgrading of structures in distress or for

Corresponding author: Ramesh Kommajosyula, M.Sc., B.E. in civil engineering, research fields: restoration of concrete structures and demolition of structures. E-mail: rameshk@varshitha.net. adopting the structure for the change in use. Use of external post tensioning for bridges restoration has become a common feature now for its advantages of higher utilisation of small sectional areas, ease in inspection of tendons, ease in application, etc.. The concept of post tensioning can be adopted for more innovative applications.

The challenge lies in adopting this technique for more innovative applications wherein conceptualization of the procedure to rehabilitate the structure is the most important aspect of the complete job.

This paper briefly describes the post-tensioning technique adopted in few projects. PT (post tensioned) technique was not adopted for such applications in India. The case studies give further insight to such similar or more innovative applications in restoration of structures. A word of caution at this stage is that, the case studies paper outlines the technique and should 
not be attempted to replicate the technique without complete analysis, study of the behavior of the existing structure under post-tensioning loads, design analysis, etc.. The application, methodology, design, etc., change from case to case basis and cannot be generalized. A wrong application without detailed analysis may result in disastrous consequences.

\section{Case 1: Removal of Alternate Columns to Increase Spans in a Commercial Complex}

The structure under this case is a five floor structure with each floor space of about 10,000 sft, was originally constructed for use as a residential structure. Hence, the column spacing was designed at $4.0 \mathrm{~m} \mathrm{c} / \mathrm{c}$. However, with the structure being on the highway, the owners realized the commercial value of the structure and decided to use as a commercial complex instead of residential. The view of the building can be seen in Fig. 1. The spacing of the columns became the main deterrent for the prospective tenants/purchasers. The restoration contractor was approached to suggest a scheme to remove alternate columns in one direction so that the spacing of columns at least in one direction is increased to $8.0 \mathrm{~m}$ instead of existing $4.0 \mathrm{~m}$. Various options were considered including:

- Providing $8 \mathrm{~m}$ long structural beam below the existing beam, however this would have seriously affected the head room in the floors;

- Encasing the beams by concrete: In this case, the beam will also be too heavy with high reinforcing steel. This would not only be cost prohibitive but also affect

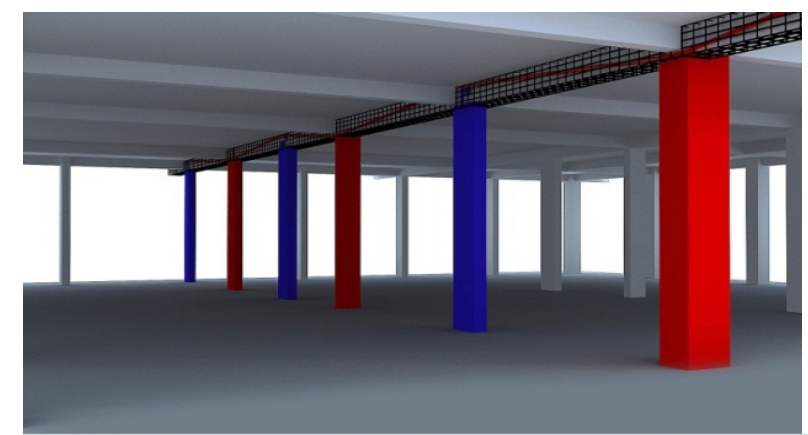

(a) Before column removal

Fig. 2 Animated views before and after column removal. the head room in the floor.

Finally, external post tensioning was considered and adopted successfully. In a row of 8 columns, 3 alternate columns were to be removed. The beams connecting these columns were encased to a thickness of $75 \mathrm{~mm}$ using micro concrete.

Fig. 2 shows the schematic of the system in animated view, adopted for removal of intermediate columns (shown in RED). In actual the continuity is maintained for 8 columns to remove 3 alternate columns.

The sequence of operations is under:

- The existing plaster on the beams was removed and surface prepared by hacking. Holes were drilled for shear connectors at spacing and $8 \mathrm{~mm}$ diameter shear connectors fixed in the drilled holes using polyester resin grout;

- Core holes were drilled in the slab along the beam at specified spacing (to enable pouring of free flow Micro concrete);

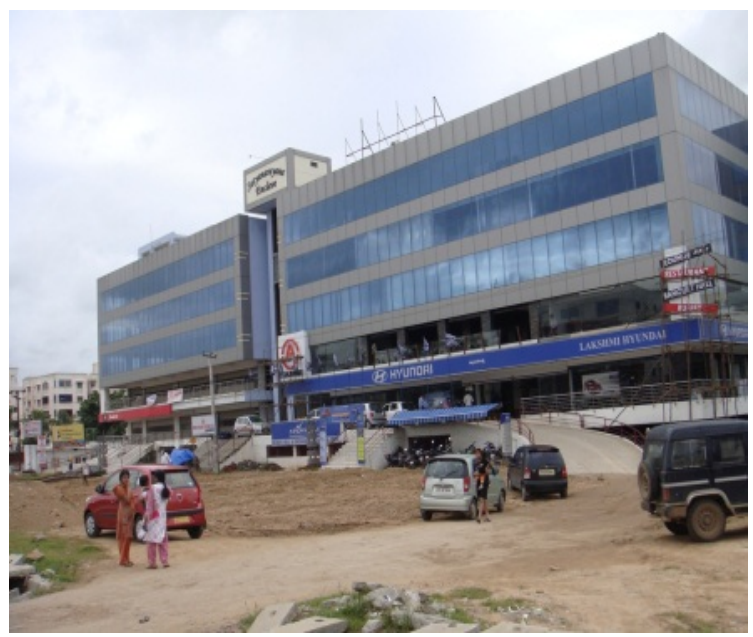

Fig. 1 View of the building.

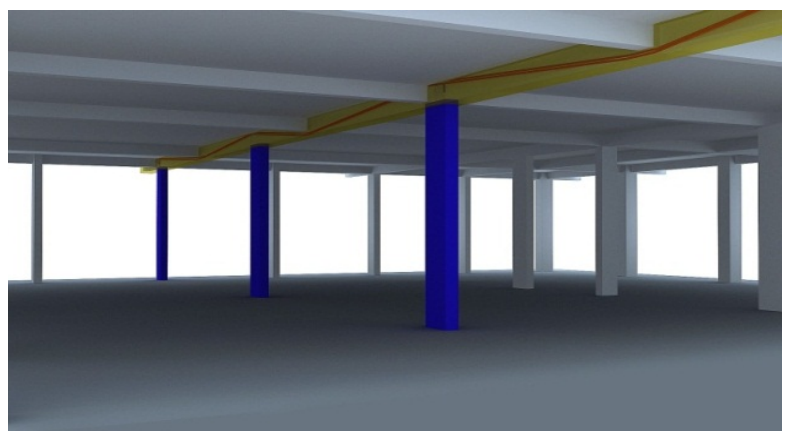

(b) After column removal 
- Reinforcement was fabricated and fixed along with post tensionmono strands (encased in HDPE (high density poly ethylene) pipe) to profile;

- End anchors of PT strands were fixed in position;

- After fabricating and fixing shuttering in position, micro concrete encasement was carried out through the core holes in the slab. The complete beam of 7 spans was carried out in single operation. Fig. 3 shows the beam after concreting [1];

- After the micro concrete [2] attained a strength of M 45 grade in 7 days, the PT strands were stressed to $60 \%$ UTS (ultimate tensile strength). Fig. 4 shows the stressing in progress [3].

Now the selected alternate columns were chipped off using electrically operated chipping machines carefully. The beams were supported on screw jacks during this operation. Fig. 5 shows the structure after the columns are removed. All the screw jacks were released carefully and deflection in beam was monitored.

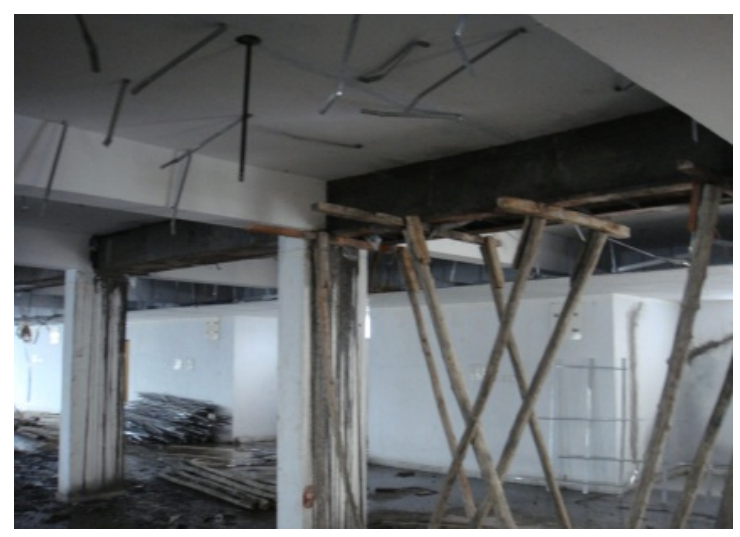

Fig. 3 After micro concreting.

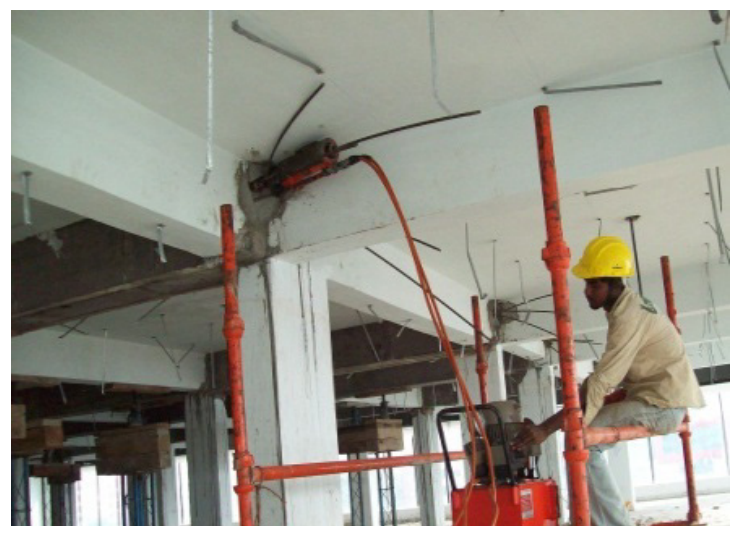

Fig. 4 Stressing in progress.

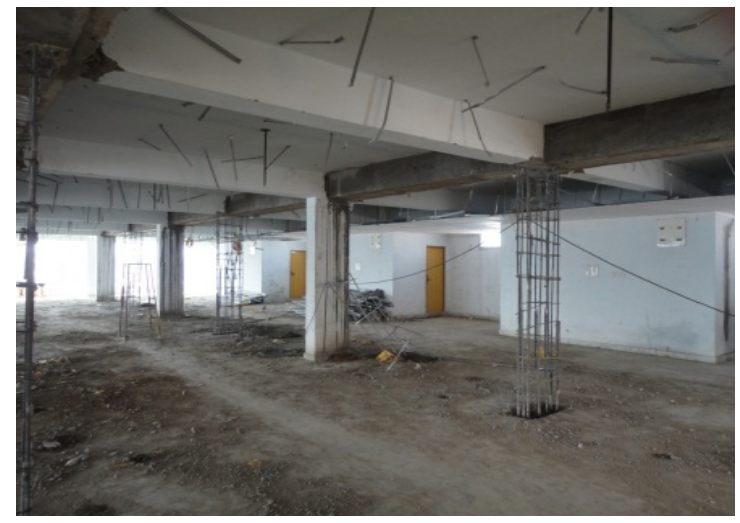

Fig. 5 Alternate column removed.

Final stressing to $90 \%$ UTS was then carried out and strands grouted. Cable profile can be seen in animated view in Fig. 2 [4, 5].

This operation was continued for all the 5 floors with 4 beams in each floor. In total, 60 columns were removed

The project was completed in three months. Within 1 month of completing the project, the clients were flooded with lease offers from major supermarket chains/hospitals/hotels. The structure which was idle for 18 months without any takers was leased out to a major supermarket chain within one month of the modification. Fig. 2 shows the animated view before and after removal of columns.

Detailed 3D modeling and structural analysis was carried out on the structure especially since the structure falls in Earthquake Zone II.

\section{Case 2: Strengthening of Pile Caps Using Post Tensioning}

This case study deals with a structure in Coastal Andhra Pradesh, India, taken over by a hotel chain for converting the building to a hotel. The new management was apprehensive of the structural stability and wanted to ascertain the load carrying capacity and structural stability for the proposed additional loading. Fig. 6 shows the structure and pile cap layout (animated).

Due to the soil condition in the area, the soil being black cotton alluvial soil, the main concern was 


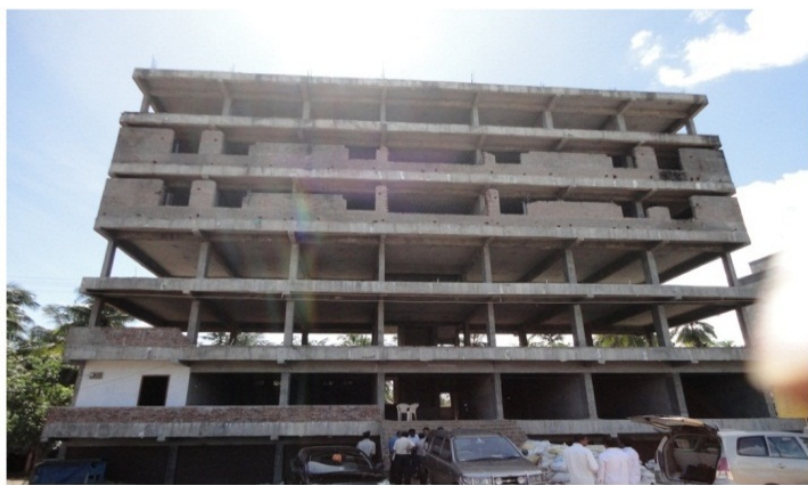

(a) The structure

Fig. 6 The structure and pile cap layout.

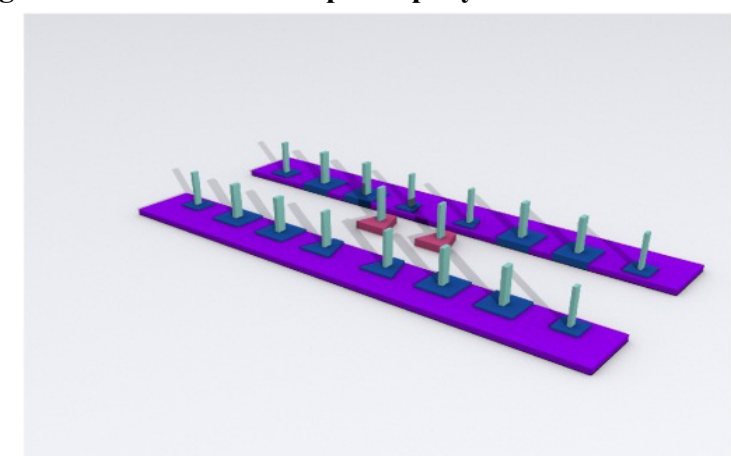

(a) Animated view of strip raft

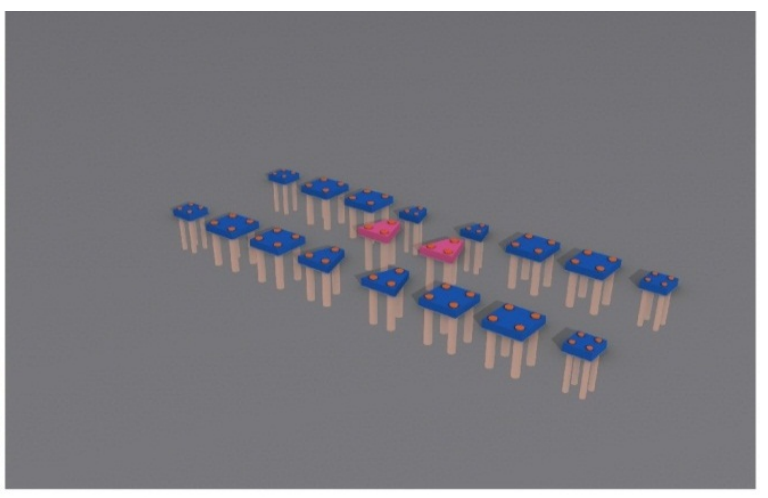

(b) Animated view of pile cap layout

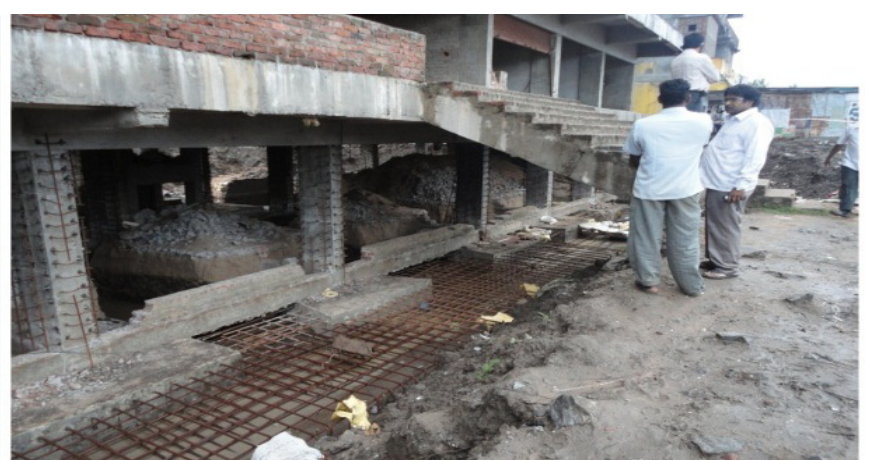

(b) Strip raft concrete in progress

Fig. 7 Animated view of strip raft and raft in progress.

stability/capacity of the foundation. In absence of any detailed "as built drawings", excavation was carried out for the footings and was found that the columns were resting on isolated pile caps supported on group of piles ranging from 3 to 5 for each pile cap. On carrying out soil investigation, it was ascertained that each pile can, at maximum carry a load of 8-10 $\mathrm{t}$ (total pile cap capacity $30-50 \mathrm{~T}$ ). With expected maximum load on the column being $100 \mathrm{~T}$, the pile cap had a capacity of only $50 \%$ of the desired requirement.

This in turn meant the pile cap needed to be strengthened for additional load carrying capacity. This could be carried out by either of the following means:

- Driving additional piles and transferring the load from existing pile cap to new piles: This option was considered not only very expensive and also practically not feasible at site;

- Combining the pile caps and converting to strip raft: This option was best suited for the project since the columns were only in 2 rows (with only 2 central columns) and both the end rows could be combined to make two strip rafts. Fig. 7 shows the strip raft concreting in progress.

\section{The Execution}

On analyzing the loading on the structure, it was concluded that if the pile caps of the two strips of columns are combined into strip rafts, it would be sufficient to carry the load of the structure. To achieve this soil around the pile caps was excavated till the bottom of the pile cap.

Core drilling of $28 \mathrm{~mm}$ diameter were carried out in the pile caps and $20 \mathrm{~mm}$ diameter rebars were inserted in the drilled holes and grouted by polyester resin grout and these rebars serve as shear connectors integrating the new pile cap with the existing pile caps. Reinforcement was then fabricated as per design tied to the shear connectors. M 35 grade concrete was carried out of $600 \mathrm{~mm}$ thick to form the strip rafts.

The main issue was the strengthening of pile caps of 
the central columns. A simple reinforced concrete beam connecting and integrating the central pile caps was found not to suffice the requirement. Increasing the depth of these connecting beams was not practically feasible.

At this stage, it was decided to induce some upward thrust to the central pile caps by using post tensioning.

Firstly a reinforced concrete beam of size 2,280 mm $\times 750 \mathrm{~mm}$ to design was cast connecting the existing pile caps as shown in the sketch above. Fig. 8 shows the schematic of PT beams and the connecting beam.

Simultaneously 3 PT beams were cast as shown in sketch with PT cables in the 3 beams to profile as shown in the Fig. 9.

After the concrete gained strength of M 30 in 7 days the PT cables were stressed to $85 \%$ UTS, thus providing uplift thrust to the central pile caps.

The PT cables were then grouted to complete the process. The structure is now complete and in service. The complete process was carried out in less than 30 days.

\section{Case 3: Restoration of a Failed Bridge}

This case refers to a bridge which had completely failed in service. The bridge is a single span $\mathrm{T}$ beam slab bridge with 3 nos beams and is located on a very important connecting road between National Highway 7 and National Highway 9, about $75 \mathrm{~K}$ M from Hyderabad, capital of the State of Andhra Pradesh.

The bridge suddenly failed by developing major vertical cracks in all the 3 beams in the centre and the deflection was observed to be about $220 \mathrm{~mm}$. The main cause being:

(1) Poor quality of concrete especially in the bottom region of the beam;

(2) Overloading of the structure (vehicle load more than designed capacity).

Fig. 10 shows the distress in the structure and deflection in the span. It was a clear failure of the structure and in normal cases the best option would be to re-construct the superstructure. However, the process involved in re-construction would take about 3-4 months starting from budget sanction to floating tenders and final completion of job. As the road cannot be blocked for such a long period causing inconvenience to heavy vehicles which use this road as the main link between two national highways, hence, emergency restoration was the only option.

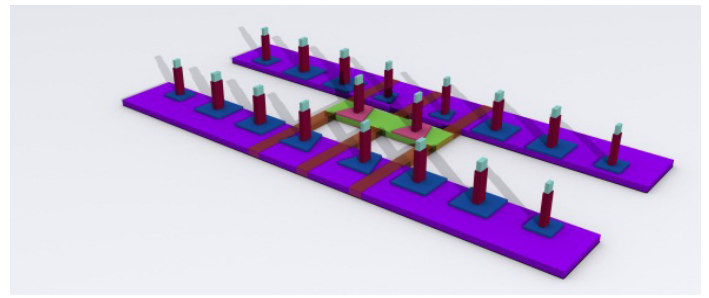

Fig. 8 Schematic showing PT beams.

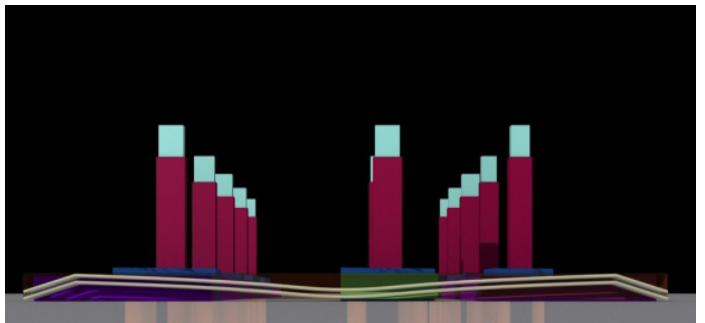

Fig. 9 Schematic showing cable profiles.

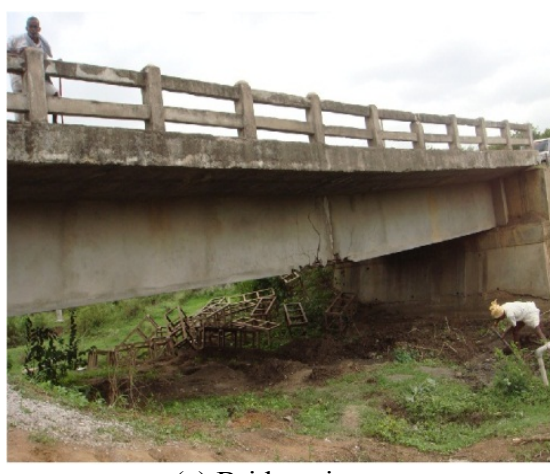

(a) Bridge view

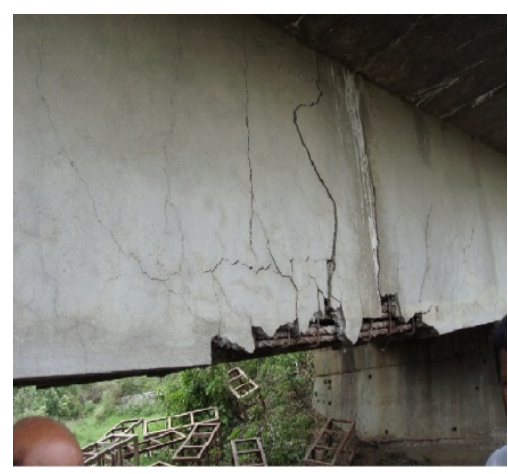

(b) Close up of distress

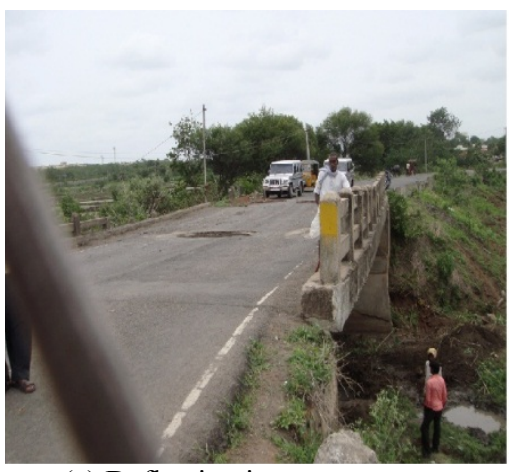

(c) Deflection in span

Fig. 10 Showing the distress in structure and deflection in the span. 
In view of the same, restoration of the structure was awarded to specialist agency to complete the project in less than one month. The restoration process involved:

(1) lifting the beams and correcting the deflection;

(2) removing the poor concrete at the bottom region of the beams;

(3) replacing the same with micro concrete;

(4) providing PT strands in the new encasement and stressing;

(5) lifting and replacement of neoprene bearings.

\section{The Execution}

As a first step, bed concreting was carried out at the locations where lifting supports are proposed to be placed to provide a firm base for the supports.

\subsection{Lifting and Correcting the Deflection}

As a first step, it is important to bring the structure to near level, i.e., the present deflection of approximately $220 \mathrm{~mm}$ to be brought to less than $20 \mathrm{~mm}$. The following procedure was adopted for carrying out the same.

Fig. 11 shows the lifting operation for deflection correction and the crack in the girder before and after completion of lifting operation.

\subsection{Encasement of Beams}

Once the structure is brought to level, the supports below the beam are transferred to below the slab (close to beams) and encasement for the beams was carried out using free flow micro concrete as per the details shown in Fig. 12. Cracks are epoxy grouted [6, 7].

Six Mono strands encased in $20 \mathrm{~mm}$ dia. High density polyethylene pipe are provided in each beam encasement. The strands are anchored to a bearing plate behind the end diaphragm beams.

After fabrication of reinforcement as per specification and fabrication of ply shuttering, Micro concrete was placed to encase each beam. Additional shear reinforcement [4] is provided to the beam to take care of the additional shear stresses due to the failed girder and so that these stresses are not transmitted to the cables.

\subsection{Stressing of Beams}

Once the encasement of beams was completed and cured for seven days, the strands in the beams were stressed to $14.70 \mathrm{t}$ each, thus inducing a stress of approximately $90 \mathrm{~T}$ in each beam $[4,8]$. This stress in the beams would not only strengthen the beams $[1,5]$, but also cater to the additional loading on the structure due to use by heavier vehicles than the load it was designed for. Fig. 13 shows the stressing ends and cables profiled before concreting $[3,9]$.

\subsection{Lifting and Replacement of Neporene Bearings}

Once the strengthening of the beams was completed, using 8 simultaneously operated hydraulic jacks (placed below the end diaphragm), the structure was lifted and the old bearings removed and replaced

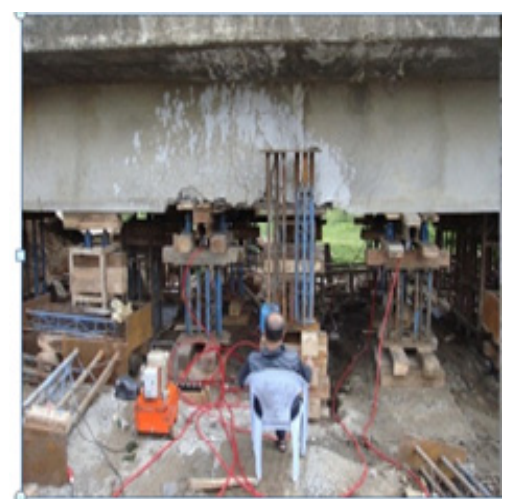

(a) Lifting in progress

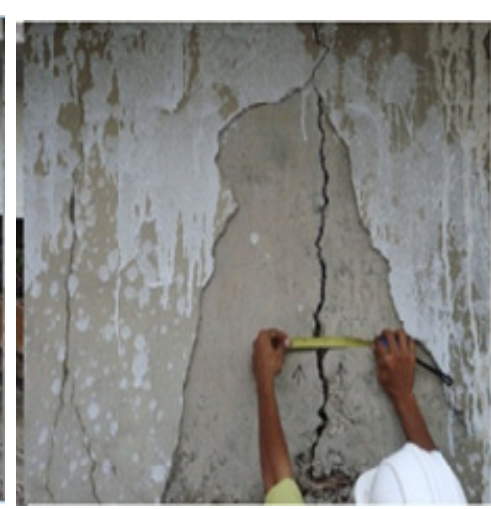

(b) Crack before lifting

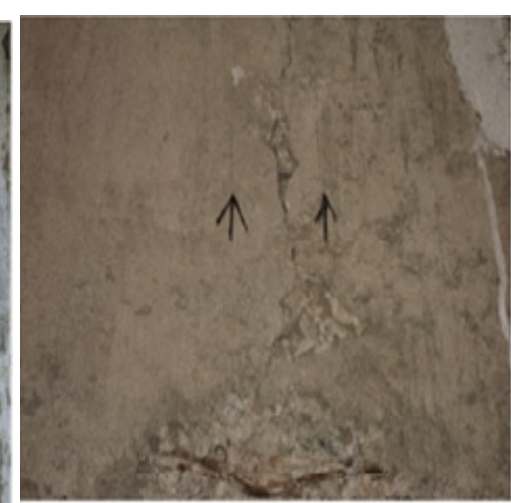

(c) Closed crack after lifting

Fig. 11 Lifting operation \& crack before and after lifting in the girder. 


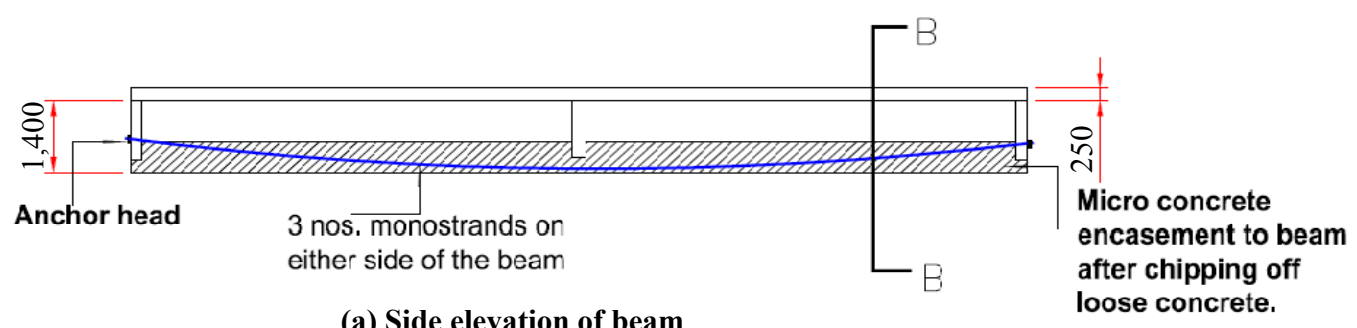

(a) Side elevation of beam after chipping of oose concrete.

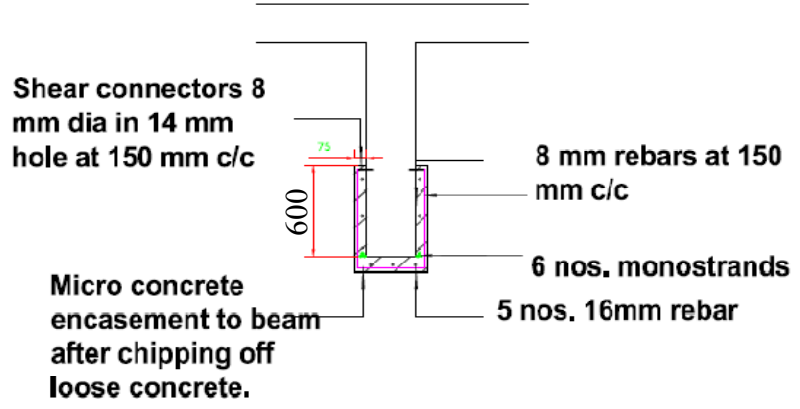

(b) Section BB (not so scale)

Fig. 12 Details of encasement of beam.

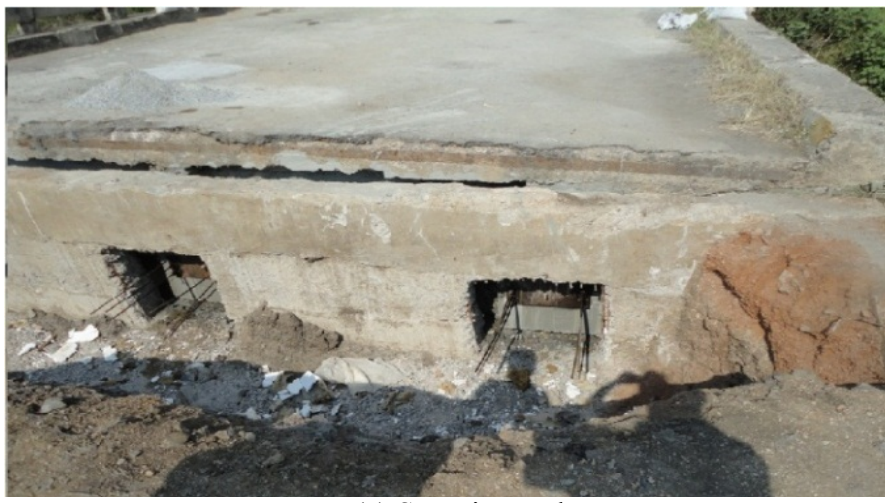

(a) Stressing ends

Fig. 13 Stressing end and cable profile before concreting.

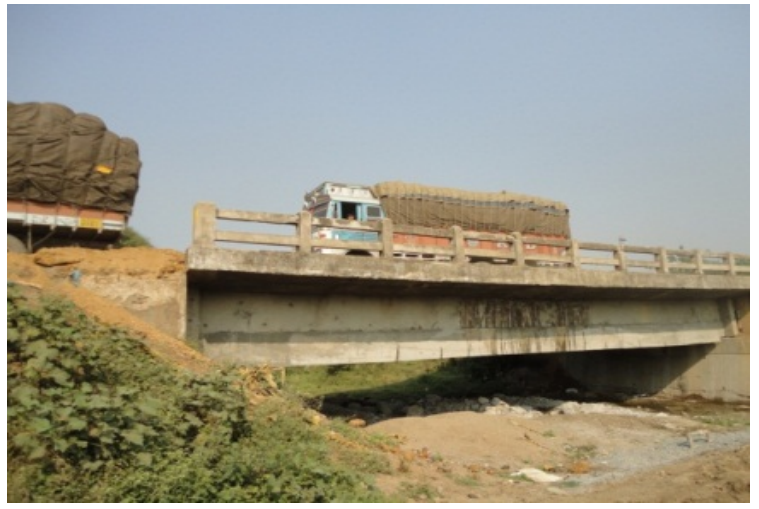

Fig. 14 Bridge in service after restoration.

with new neoprene bearings. Restored bridge in operation can be seen in Fig. 14.

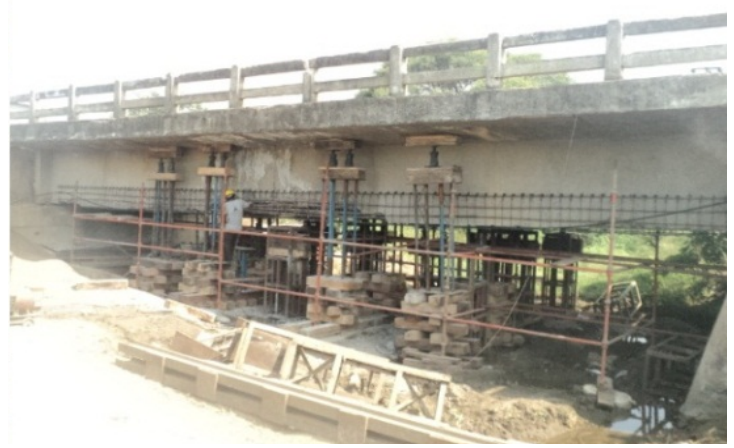

(b) Cables profiled

\section{Case 4: Stabilizing Rocks by Post-Tensioning}

At Durga Malleswari temple, Vijayawawada, India it was proposed to widen the road on to the hill by excavating part of the hill, which would enable easing traffic congestion especially during the peak festival season. This required blasting the rock to widen the road. In the process of uncontrolled blasting, the rocks had become very unstable and reached a point of no return. At this stage, it was very difficult to stabilize the rocks by the proposed conventional method of rock bolting as not only it was very difficult to access the 
rocks at the height of $60 \mathrm{~m}$ it was impossible to erect scaffolding to such heights. Further, there is a great risk of further destabilizing the rocks during the drilling process. Fig. 15 shows the status of rocks after blasting

Innovative technique of use of post tensioning method [10] was adopted and executed successfully. The process involved the following steps:

- Drilling pair of hole at a spacing of $1.0 \mathrm{~m} \mathrm{c} / \mathrm{c}$ in stable rocks both top and bottom with a spacing of 300 $\mathrm{mm}$ between each hole in the pair;

- Depth of hole is $2.0 \mathrm{~m}$;

- Fixing $3 \mathrm{~m}$ long HT (High Tensile) strands in the drilled hole using polyester resing rout;

- Fixing anchor blocks both top and bottom to each pair of HT strands;

- Connecting the corresponding anchor blocks at top and bottom with HT Strand (PE coated HT strand).
Locking the same with barrel and wedge system;

- The strands are stressed to approximately 4.0 tons each and thus effectively pressing down the rocks and locking the same;

- Chain link mesh was spread over the strands securely tied to the strands and anchors. Chain link mesh is mainly to stop any smaller pieces of rock rolling down.

The complete job was carried out in less than 90 days, well before the rush season of the temple and the total stretch completed was $420 \mathrm{~m}$. Fig. 16 shows the netting in progress and after fixing and stressing of strands.

\section{Case 5: Restoration of Sumatra Quake Affected Austin Strait Bridge, Andaman}

The Tsunami of December 2004 had created a great deal of loss in both human lives and property damage

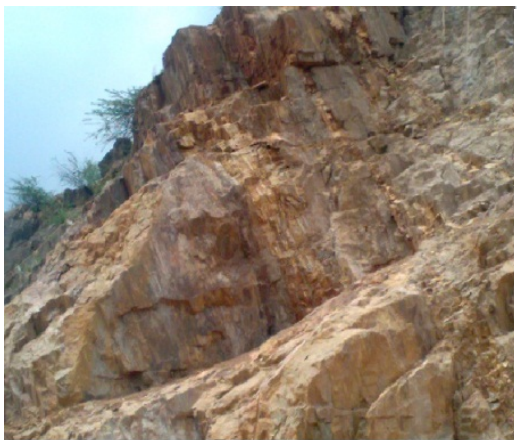

(a) Loose rocks view 1

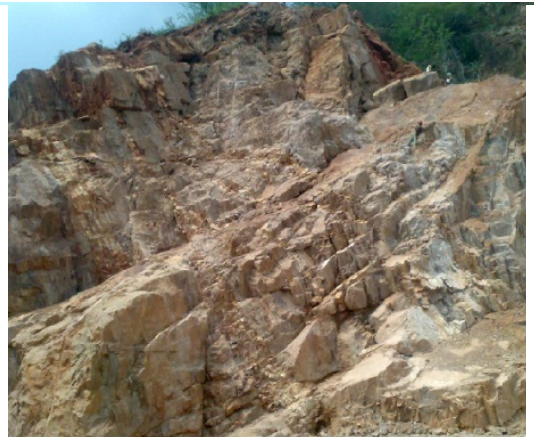

(b) Loose rocks view 2

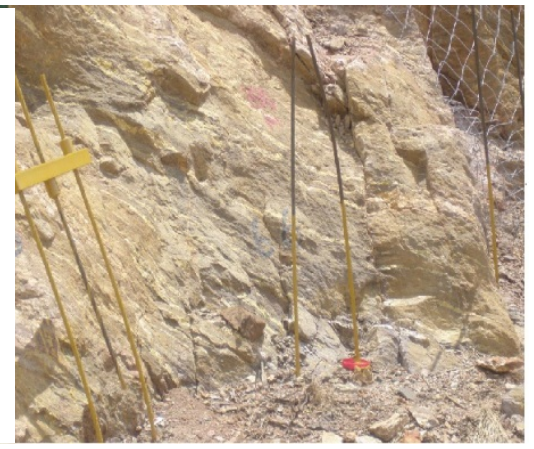

(c) Ground anchors fixed

Fig. 15 Loose rocks after blasting, fixing of HT anchor.

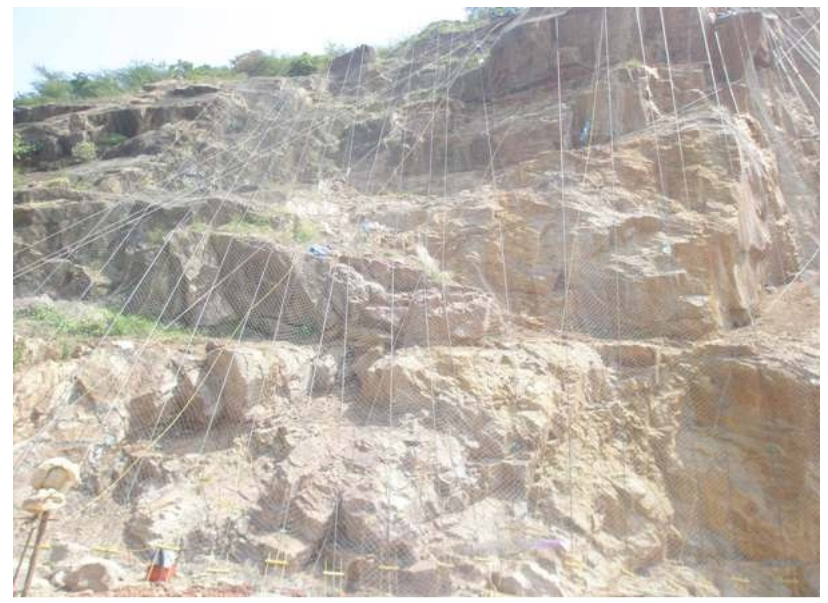

(a) Netting and fixing strands in progress

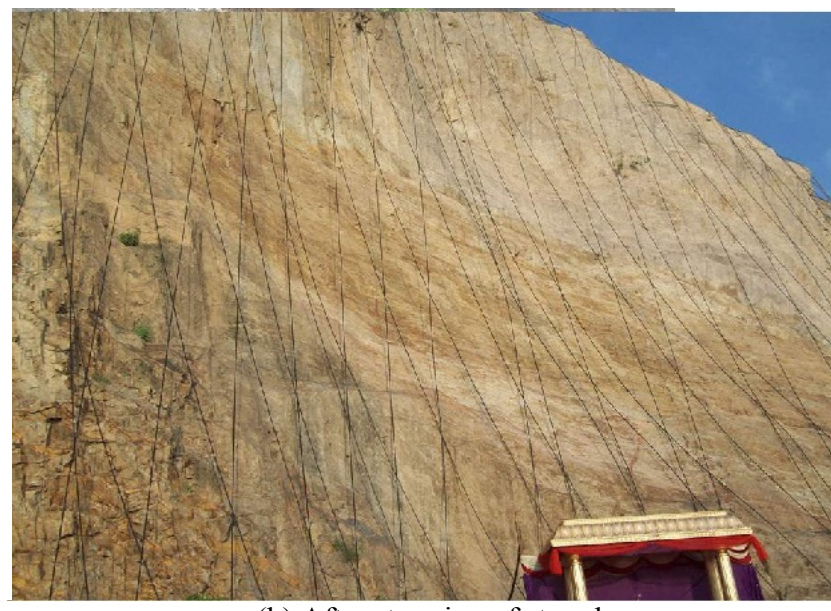

(b) After stressing of strands

Fig. 16 Netting and strand fixing and after stressing of HT strands. 
in Indonesia, India (including Andamans), Sri lanka and to some extent even South Africa. As regards to civil structures the damage was mainly because of the earthquake (popularly known as Sumatra quake) preceding the tsunami. One of the structures that were affected badly by the quake was the Austin Strait Bridge connecting the two northern islands of Andaman namely, the north Andaman and Diglipur Island. This bridge is the main lifeline to reach the Diglipur Island by road. Fig. 17 shows the bridge immediately after the quake.

The Austin Strait Bridge was constructed in the year 2002 and the main features of the structure are as follows:

- No. of spans:13 spans;

- Span: $20.60 \mathrm{~m}$;

- Super structure: T-beam structure with 4 nos. beams;

- Sub-structure: 2 nos. piers supported on 4 nos. piles;

- Bearings: neoprene bearings.

\section{The Damage}

\subsection{Piers and Piles}

There was no appreciable damage to piers \&pile cap however on observing the levels of the pile cap and pier cap it was observed that the foundation was slightly displaced from its original position and there was a slight tilt in some of the piers. The damage to the sub-structure though appreciable may not have affected the stability of the structure however it was proposed to carry out under-water inspection of all the piles for any distress features that can affect the structure at a later date.

The few cracks that were observed on the pile cap were proposed to be repaired by epoxy injection grouting and repairing the spalled regions by epoxy mortar.

\subsection{Pedestals and Bearings}

Some of the pedestals were damaged by the sudden

impact of the super structure on it due to the earthquake. This impact not only damaged the pedestals but also portion of the super structure beam. This can be clearly seen in Fig. 18. The impact was so heavy that the beams were resting on the pier cap and not on the pedestal.

\subsection{Damage to Beams}

The lateral and longitudinal movements in the super structure had damaged most of the neoprene bearings either by crushing or deforming beyond limits.

\subsection{Super Structure}

During the process of the displacement of the super structure the bearing ends of the main beams were badly damaged. However, the damage was mostly restricted upto the end diaphragm beam. The damage done to the super structure can be seen in the mis-aligned bridge is shown in Fig. 19.

\subsection{Expansion Joints}

The expansion joints were badly damaged during the

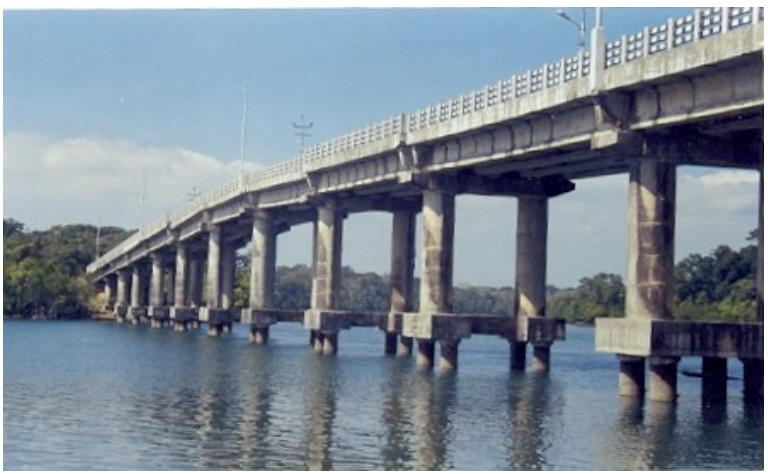

Fig. 17 View of the bridge.

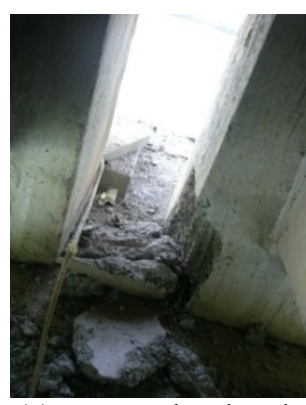

(a) Damaged pedestal

Fig. 18 Damage to pedestal and beam jumping off pedestal.

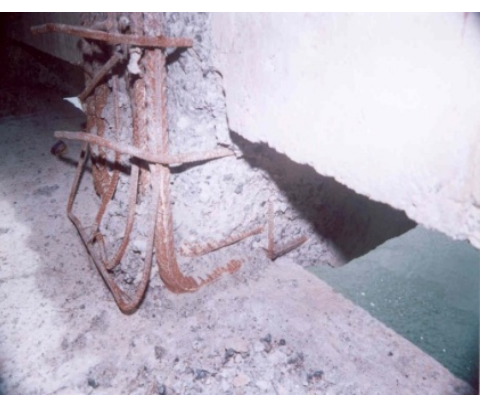

(b) Damaged beam. 


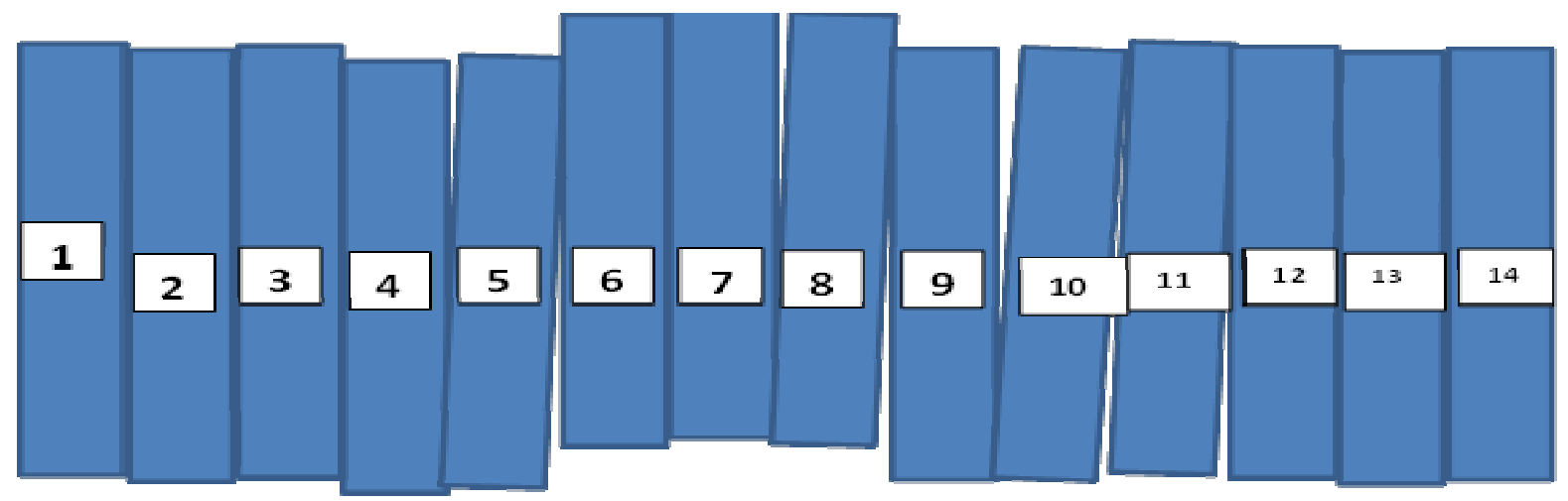

Fig. 19 Sketch showing alignment after quake.

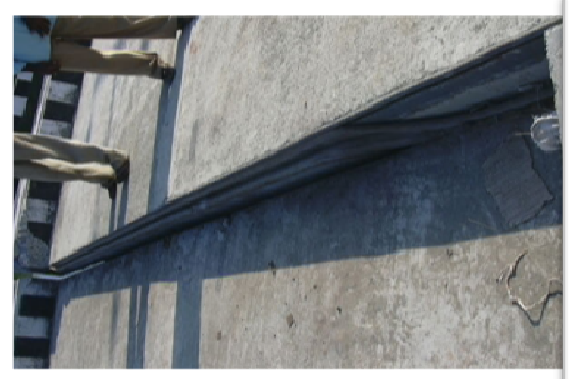

(a) Expansion joints badly damaged (vertical split)

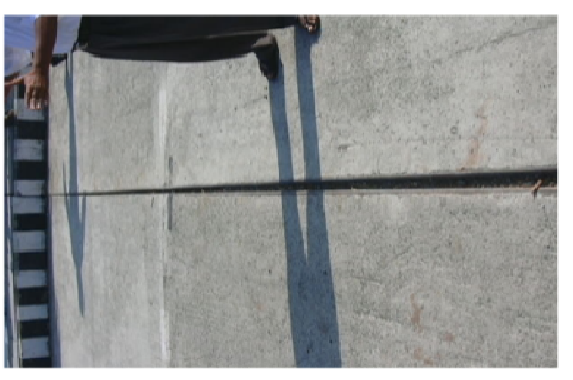

(b) Expansion joint opened up

Fig. 20 Expansion joints badly damaged.

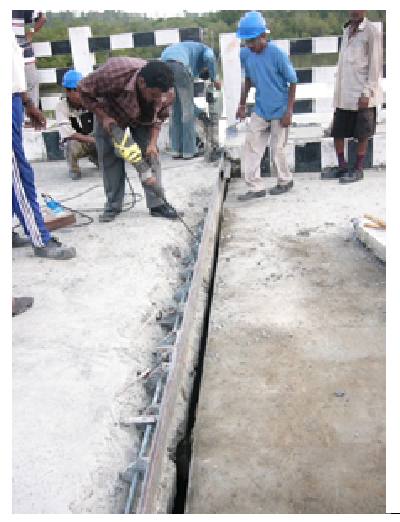

(a) Removal of expansion joints

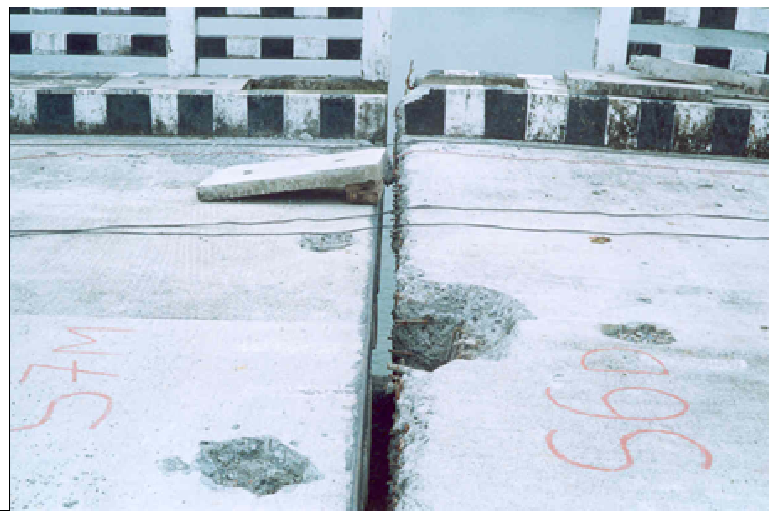

(b) Clearing of joint

Fig. 21 Removal of expansion joints.

process of displacement of the total structure. In most of the effected spans, the neoprene rubber joint of the strip seal was torn/damaged (Fig. 20). It was necessary to replace the same by a new one.

\section{The Execution}

The following sequences of operations were carried out for restoring the bridge:

(1) Step 1
As a first step, all expansion joints were chipped and removed and sufficient. Gap was created between the spans. At the same time, access hole was made in the deck slab to enable the workmen to reach the pier cap top. Fig. 21 shows the chipping of expansion joints in progress;

(2) Step 2

Since there is a longitudinal curve in the structure measurements were recorded for all the pedestals and 


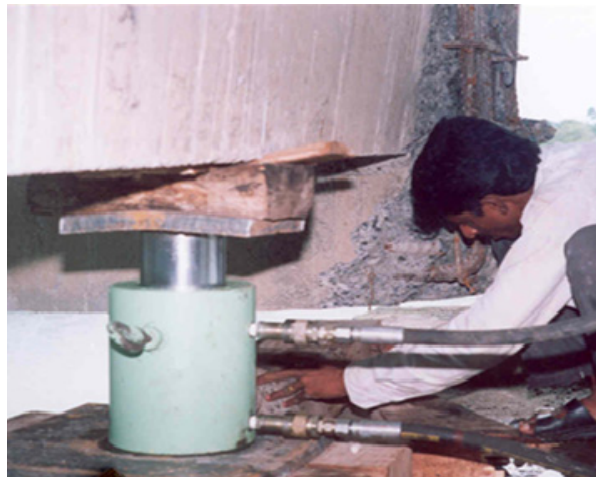

(a) Lifting and alignment of spans

Fig. 22 Lifting and alignment of spans.

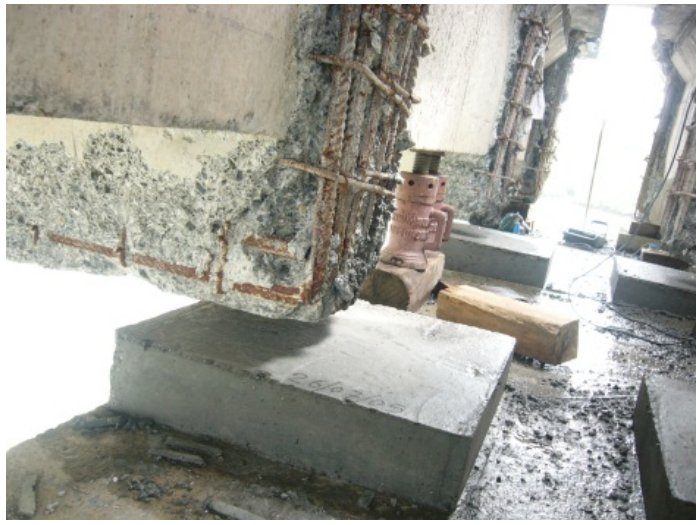

Fig. 23 After casting new pedestals.

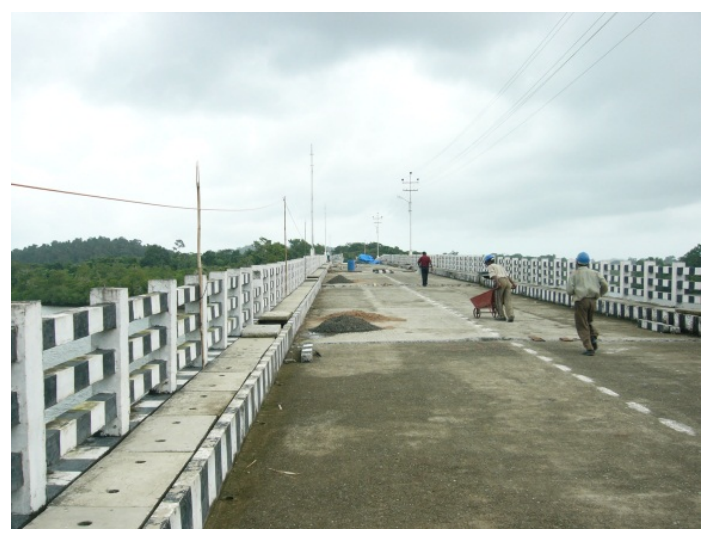

Fig. 24 The aligned bridge.

new levels of the pedestals with the same slope were marked on the pier cap;

(3) Step 3

In a phased manner lifting and alignment of spans was taken up with two spans at a time. Alignment of spans was started from the centre span proceeding either side. Each span was lifted from its position to a height comfortable enough for casting the new

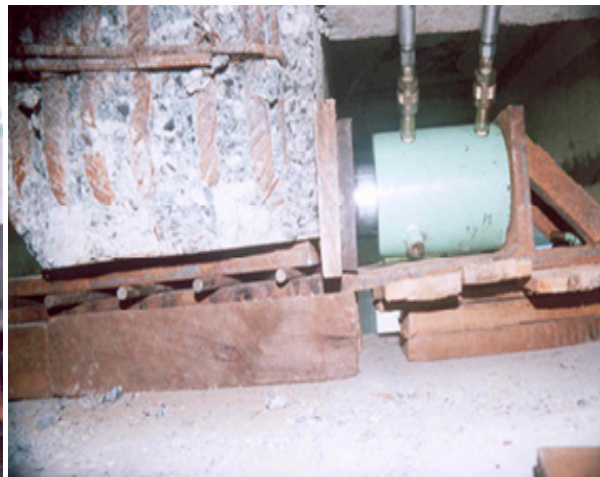

(b) Lateral pushing of span

pedestals. The lifted span was moved laterally/longitudinally to align the same to its correct position.

The rolling arrangement for lateral movement of the structure is shown in Fig. 22;

(4) Step 4

The damaged portion of the main girders of the span was repaired using free flow micro-concrete after removing the loose and spalling portion of the concrete;

(5) Step 5

New pedestals were cast to as per correct alignment on the pier cap after chipping and removing the old pedestals. The new pedestals can be seen in Fig. 23;

(6) Step 6

After the pedestals had attained sufficient strength, the spans were lowered on the new pedestals after fixing new neoprene bearing pad;

(7) Step 7

Once all the spans were aligned and lowered on the pedestals, new strip seal expansion joints were fixed in position. Fig. 24 shows the aligned bridge.

\section{Conclusions}

The case studies mentioned above are some special and innovative applications for restoration/rehabilitation of structures. Full advantage of post tensioning was applied in the above projects. There may be many more examples of such applications. 
The concepts as applied in the above case studies can be further implemented in many more such projects with innovative design and techniques. If carefully applied, post tensioning technique has innumerable applications in restoration/rehabilitation of structures. Post tensioning technique is also being used for carbon laminates for more effective use in Restoration of Structures.

Therefore in conclusion, post tensioning has not only revolutionized the construction industry in India, but can also be effectively used for restoration and rehabilitation of structures.

\section{Acknowledgments}

We acknowledge the contribution of the following experts and friends in the above projects: (1) Dr. M.R. Madhav, professor Emeritus, JNT University; visiting professor, IIT, Hyderabad; (2) Mr. Zaki Ahmed, M/s Zaki Associates, Hyderabad; (3) Mr. K. Narasimha Raju, BE (IIT Mumbai), chartered structural engineer, designer for most of the above case study projects; (4) Mr. Kondala Rao (Retd.), chief engineer and advisor to government of Andhra Pradesh.

\section{References}

[1] A.F. Daly, I.W. Witarnawan, A method for increasing the capacity of short and medium span bridges, in: 10th REAAA (Road Engineering Association of Asia and Australasia)
Conference 2000, Tokya, Japan, Sep. 4-9, 2000.

[2] Concrete Repair Manual, 3rd ed., ICRI (International Concrete Repair Institute), International Concrete Repair Institute, 1997.

[3] M.H. Harajli, Strengthening of concrete beams by external prestressing, PCI Journal 38 (6) (1993) 76-88.

[4] K.H. Tan, C.K. Ng, Effect of shear in externally prestressed beams, ACI Structural Journal 95 (2) (1998) 116-128.

[5] A. Miyamoto, K. Tei, H. Nakamura, Bull JW behavior of prestressed beam strengthened with external tendons, Journal of Structural Engineering 126 (9) (2000) 1033-1044.

[6] P.H. Emmons, Concrete Repair and Maintenance Illustrated, Construction Publishers \& consultants, Kingston, MA, 1993.

[7] ACI Committee E 706, Structural Crack Repair by Epoxy Injection, American Concrete Institute, Report No.: ACI RAP-1, 2003.

[8] H. Nordin, Strengthening Structures with Externally Prestressed Tendons, Technical report 2005-06, Department of Civil and Environmental Engineering, Luleå University of Technology, 2006.

[9] T. Aravinthan, Y. Hemada, K. Uethira, Advances in prestressed concrete bridges with external prestressing, in: G.J. Hancock, M.A. Bradford, T. Wilkinson, B. Uy, K.J.R. Rasmussen (Eds.), Advances in Structures: Steel Concrete, Composite and Aluminium (ASSCCA), A.A. Balkema Publishers, Sydney, Austrialia, 2003, pp. 841-846.

[10] M. Virlegeux, External presstressing historical and modern applications, in: E. Conti, B. Foure (Eds.), Workshop on Behaviour of External Presstessing in Structures, France, June 9-12, 1993, pp. 13-42. 